\title{
EFEK PEMBERIAN MASSAGE BAYI DAPAT MENINGKATKAN KUALITAS TIDUR BAYI NORMAL USIA 0 - 6 BULAN DI POSYANDU PERMATA HATI
}

\author{
Siti Muawanah ${ }^{1)}$, Futhri Rifa Zaimsyah ${ }^{1)}$, Nova Relida Samosir ${ }^{1)}$ \\ 1)Progam Studi Fisioterapi, Fakultas Kedokteran dan Ilmu Kesehatan, \\ Universitas Abdurrab \\ Email :siti.muawanah@univrab.ac.id
}

\begin{abstract}
ABSTRAK
Tidur adalah salah satu kebutuhan bayi atau anak yang sama pentingnya dengan kebutuhan utama lainnya. Salah satu cara untuk memenuhi kebutuhan tidur bayi adalah dengan Massage (sentuhan). Sentuhan pada kulit akan merangsang peredaran darah dan akan menambah energi gelombang oksigen yang lebih banyak dikirim ke otak sehingga memacu system sirkulasi dan respirasi menjadi lebih baik. Rasa nyaman dan rileks akibat massage akan meningkatkan kualitas tidur. Selain itu dapat meningkatkan produksi Asi, meningkatkan berat badan, meningkatkan daya tahan tubuh, pada bayi 0-6 bulan. Tujuan penelitian ini untuk membuktikan bahwa massage mampu meningkatkan kualitas tidur bayi 0-6 bulan. Metode pengabdian dilakukan dipoyandu permata hati 13orang dalam 1 kelompok diberi intervensi dengan massage bayi. pada bayi normal 0-6 bulan. Simpulan pada pengabdia ini bahwa ada efek pemberian massage bayi terhadap kualitas tidur bayi normal 0-6 bulan.
\end{abstract}

Kata kunci : tidur, massage bayi, kualitas tidur, kuesioner

\begin{abstract}
Sleep is one of the needs of a baby or child that is as important as other primary needs. One way to fulfill your baby's sleep needs is by massage. Touch on the skin will stimulate blood circulation and will increase the oxygen wave energy that is more sent to the brain so that the circulation system and respiration spur better. Feeling comfortable and relaxed due to massage will improve sleep quality. In addition, it can increase the production of Asi, increase body weight, increase endurance, in infants 0-6 months. The purpose of this study is to prove that massage can improve the quality of sleep for babies 0-6 months. The method of dedication was carried out by tearing the hearts of the 13 people in one group and were intervened with infant massage. in normal infants 0-6 months. The conclusion of this service is that there is the effect of giving a baby massage to the sleep quality of a normal baby 0-6 months.
\end{abstract}

Key words: sleep, baby massage, sleep quality, questionaire 


\section{PENDAHULUAN}

Anak adalah penerus estafet bangsa, maka sangat penting menciptakan generasi sehat sejak usia dalam kandungan. Sejak di lahirkan, bayi memiliki tiga kebutuhan yang harus dipenuhi orang tuanya yaitu, terpenuhinya kebutuhan fisik-biomedis yang berguna untuk pertumbuhan otak system sensorik dan motoriknya, kebutuhan emosi kasih sayang berguna untuk kecerdasan emosi, inter dan intra personalnya, stimulasi untuk merangsang semua kerja sensorik dan motoriknya (Rudolp, 2006).

Mengingat akan pentingnya waktu tidur bagi perkembangan bayi, maka kebutuhan tidurnya harus benar-benar terpenuhi agar tidak berpengaruh buruk terhadap perkembangannya. Setiap proses tidur, baik tidur malam atau tidur siang, terjadi perubahan dari fungsi otak. Tidur adalah salah satu kebutuhan bayi atau anak yang sama pentingnya dengan kebutuhan utama lainnya, didalam kehidupan sehari-hari seperti makan, minum, sandang, rasa aman, kasih sayang, dan lainnya. Kebutuhan bayi untuk tidur yang cukup tidak bisa di anggap remeh atau di tempatkan urutan prioritas paling bawah, karena pertumbuhan dan perkembangannya sangat tergantung dari tidur. Menurut Joesoef dalam Yudana (2003), selama fase bayi, pertumbuhan sel-sel syaraf belum sempurna sehingga diperlukan waktu tidur lebih lama untuk perkembangan syaraf, pembentukan sinaps, dan sebagainya. Otak bayi tumbuh tiga kali lipat dari keadaan saat lahir atau $80 \%$ dari otak orang dewasa di tahun pertamanya. Kondisi ini hanya terjadi satu kali saja seumur hidup. Dimana pada saat tidur sekitar $80 \%$ terjadi pertumbuhan otak dan fisik. Oleh karena itu tidur berkualitas, penting bagi bayi dalam proses pertumbuhan optimal karena pada saat tidur aktifitas regenerasi sel-sel tubuh dan tumbuh kembang otak berlangsung pada puncaknya. Begitu juga sebaliknya, jika bayi kekurangan tidur akan berdampak buruk terhadap pertumbuhan dan perkembangannya, di mana bayi tidak tumbuh secara optimal. Sehingga untuk tumbuh kembang yang maksimal bayi membutuhkan waktu istirahat yang cukup (Wuspita, 2006).

Tidur dengan kualitas dan kuantitas yang baik akan banyak membantu perkembangan bayi. Biasanya anak-anak dengan usia yang sama akan mempunyai rentang waktu tidur yang kurang lebih sama (Handjani, 2010). Satu penelitian Sekartini dkk pada 2004-2005 di lima kota besar di Indonesia (Jakarta, Bandung, Medan, Palembang dan Batam), mengungkapkan, sebanyak 72,2 persen orang tua menganggap masalah tidur pada balita bukan masalah. Penelitian yang sama juga mengungkapkan, ada sekitar 44 persen balita yang mengalami gangguan tidur seperti sering terbangun di malam hari dan kurang tidur. Dr Rini memaparkan bahwa bayi dikatakan mengalami gangguan tidur jika pada malam hari tidurnya kurang dari 9 jam, terbangun lebih dari 3 kali dan lama terbangunnya lebih dari 1 jam. Selama tidur bayi terlihat selalu rewel, menangis dan sulit jatuh tidur kembali. Bagitu juga sebaliknya bayi dikatakan cukup tidur jika jatuh tertidur dengan mudah di malam hari dan terbangun dengan mudah di pagi hari dan tidak memerlukan tidur siang yang melebihi kebutuhan sesuai perkembangannya (Hidayat, 2008).

Beberapa faktor yang mempengaruhi kualitas tidur pada bayi baik dalam diri ataupun dari luar bayi itu sendiri di antaranya faktor : lingkungan, nutrisi, kondisi fisik, dan penyakit. Jika faktor-faktor ini tidak dapat ditangani sehingga membuat bayi kekurangan tidur yang akan berdampak buruk terhadap bayi pada fisik, emosi, kognitif dan gerak, dan bahkan keluarga juga, dimana akan menimbulkan stress dan depresi terhadap ibu bayi yang baru melahirkan (Heath dan Bainbridge, 2006). 
Salah satu cara untuk memenuhi kebutuhan tidur bayi adalah dengan Massage. Bayi yang dimassage akan dapat tidur dengan lelap, sedangkan pada waktu bangun daya konsentrasinya akan lebih penuh Massage merupakan sentuhan yang diberikan pada jaringan lunak yang memberi banyak manfaat bagi anak maupun orang tua. Massage pada bayi berfungsi untuk membantu rileksasi baik local maupun general, daerah yang dimassage secara refleks akan terjadi dilatasi pembuluh darah, dimana sirkulasi darah akan meningkat. Sentuhan pada kulit akan merangsang peredaran darah dan akan menambah energi gelombang oksigen yang lebih banyak dikirim ke otak sehingga memacu system sirkulasi dan respirasi menjadi lebih baik. Rasa nyaman dan rileks akibat massage akan meningkatkan kualitas tidur. Selain dapat membuat tidur lelap, massage bayi mempunyai efek positif yang lain yaitu mengubah gelombang otak secara positif, memperbaiki sirkulasi darah dan penapasan sehingga meningkatkan aliran oksigen dan nutrisi menuju sel, meningkatkan produksi Asi, meningkatkan berat badan, meningkatkan daya tahan tubuh, dan lain-lain (Nurheti Yuliarti 2010). Selain dapat membuat tidur lebih lelap, terapi massage sebagai bagian dari pengobatan alternatif, yang diterima secara empiris sebagai sarana untuk membantu pertumbuhan, mengurangi rasa sakit, meningkatkan kesiagaan, mengurangi depresi dan meningkatkan fungsi sistem imun pada bayi yang baru lahir. Massage akan memberikan keuntungan yang lebih besar jika dilakukan setiap hari sejak kelahirannya sampai usia 6-7 bulan. Keuntungan dari Massage ini dapat dilakukan dengan mudah dengan beberapa kali latihan. Selain itu juga tidak memerlukan biaya yang mahal (Cline, 2001).

Peran fisioterapi pada masa sekarang tidak hanya mulai merambah pada subyek sehat, karena peran fisioterapi sekarang mampu menjangkau lebih dalam pada aspekaspek kehidupan masyarakat lainnya, diantaranya peran fisioterapi pada bidang kesehatan ibu dan anak mulai dari masa mengandung, masa melahirkan, masa menyusui, dan bagaimana cara merawat bayi dalam tumbuh kembang. Untuk itu penulis tertarik untuk mengetahui efek pemberian massage bayi terhadap kualitas tidur pada bayi normal usia 0 - 6 bulan. Rumusan Masalah yang akan diteliti adalah : "Apakah ada efek pemberian massage bayi terhadap peningkatan kualitas tidur pada bayi normal usia 0-6 bulan". Tujuan Pengabdian : Untuk memberikan edukasi pada ibu bayi akan pentingnya massage bayi buat bayi dan untuk mengetahui efek massage pada bayi normal usia $0-6$ bulan.

\section{TINJAUAN PUSTAKA}

\section{Fisiologis Tidur Bayi 0 - 6 Bulan}

Fisiologi tidur merupakan pengaturan kegiatan tidur yang melibatkan mekanisme cerebral yang secara bergantian agar mengaktifkan pusat otak untuk tidur dan bangun. Secara fisiologis ada beberapa hal yang terjadi saat bayi tidur di antaranya yaitu fisiologis tidur dan bangun di otak. Tidur merupakan aktivitas dari area tertentu di otak yang menyebabkan tidur, dari pada masukan sensorik yang menurun di korteks serebri. Stimulasi pada area ini akan menghasilkan tidur, sebaliknya kerusakan akan mengakibatkan gangguan tidur. Control tidur tergantung pada dua mekanisme cerebral yang bekerja saling berlawanan antara satu dengan yang lainnya. Kedunya secara intermiten mengaktivasi pusat luhur di otak yang mengontrol tidur dan terjaga. Satu mekanisme menyebabkan individu terjaga, sedangkan mekanisme lainnya menyebabkan individu tertidur. Siklus tidur dan bangun di control oleh aktivitas nuron di dalam sisitem reticular activating system (RAS). RAS terdiri dari system retikularis batang otak, posterior hipotalamus dan basal otak depan. System pengaktifan reticular (reticular activating system/RAS) terletak dalam batang otak atas (uper brainstem). RAS di yakini 
mengandung sel-sel khusus yang mempertahankan keadaan siaga dan terjaga. $R A S$ menerima input rangsang sensori visual, auditori dan nyeri serta rangsang raba. Aktivitas dari serebral kortek (seperti emosi dan proses berfikir) juga menstimulasi $R A S$.

Mekanisme tidur dan bangun sesungguhnya belum di ketahui secara pasti. Aktivitas neuron di pons, mid brain, dan posterior hipotalamus penting untuk keadaan bangun. Sedangkan aktivitas di medulla sangat penting untuk stimulasi keadaan tidur. Tidur dapat juga ditimbulkan oleh pelepasan serotonin dari sel khusus dalam raphe sleep system pada pons dan bagian medial dari otak depan. Area otak ini di sebut juga sebagai regio pengsinkronan bulbar (bulbar synchronizing region/BSR). Maka seseorang dapat mempertahankan keadaan terjaga atau keadaan tidur bergantung pada keseimbangan impuls yang diterima dari pusat otak (seperti, berfikir), reseptor sensori perifer seperti stimulus bunyi dan cahaya dan system emosi. Seorang mencoba untuk tidur, akan menutupkan matanya dan mengatur posisinya sehingga rilek.

Stimulus pada $R A S$ menjadi menurun. Jika ruangan di gelapkan dan tenang, maka aktivasi $R A S$ akan semakin menurun. Pada suatu saat $B S R$ akan mengambil alih, sehingga menyebabkan individu menjadi tertidur. Lateral pons dan area retikularis di medial medulla merupakan area yang sangat active salama priode tidur REM dan sangat kurang active pada tidur non REM. Sel-sel neuron di medulla yang mengontrol tidur REM, di duga berpengaruh terhadap tonus otot pada waktu tidur REM, yaitu melalui aktivasi neuron di batang otak dan inhibisi motor neuron di medulla spinalis. Secara farmakologik, kini sudah ada bukti bahwa tidur nonREM sangat berhubungan dengan mekanisme serotoninergik dan tidur REM dipengaruhi oleh adrenergic. Sebagai contoh, pemberian serotonin dapat mengurangi latensi tidur secara bermakna, sebaliknya kerusakan area serotonin di pons menyebabkan insomnia. Injeksi asetilkolin kedalam pons akan menimbulkan tidur REM. System katekolamin (noradrenalin dan dopmina) juga mempunyai peran penting pada keadaan bangun dan tidur REM. Konsentrasi norepneprin dan serotonin di korteks mencapai puncak pada waktu bangun, terendah pada tidur REM dan intermediet pada tidur nonREM. Sebalik neuron kolinergik melepaskan asetilkolin dengan kadar yang tinggi pada tidur REM dan waktu bangun dan terendah pada waktu tidur non REM.

\section{Fisiologis Metabolisme Pada Saat Tidur}

Metabolisme tubuh menurun saat bayi tidur karena adanya penurunan aktivitas organ-organ tubuh tersebut selama tidur. Akan tetapi pada periode tidur REM metabolisme meningkat karena tidur REM merupakan tidur aktif. Tidur merupakan interaksi inti yang kompleks dari multiple system neurotransmitter, dan system regulasi tidur dengan mekanisme lain, sebagai contoh mekanisme yang mengatur temperature, pola pernapasan dan tekanan darah. Kira-kira 2/3 kehidupan bayi baru lahir di gunakan untuk tidur. Seluruh kejadian selama tidur merupakan refleksi dari aktivitas neuron tertentu di susunan saraf pusat, yang berubah secara dramatis sesuai dengan perkembangan bayi. Oleh karena itu tidur sangat berhubungan dengan perkembangan anak dan sekaligus merupakan jendela dari perkembangan otak anak selanjutnya.

\section{Massage Bayi 0 - 6 Bulan}

Massage merupakan sentuhan yang diberikan pada jaringan lunak yang memberi banyak manfaat bagi anak maupun orang tua. Massage adalah sentuhan dan tekanan yang akan merangsang peredaran darah dan menambah energi. Massage merupakan kebutuhan yang sama pentingnya pada bayi sebagaimana kebutuhan lain seperti makan dan minum. 
Message merupakan alat komunikasi untuk menjalin ikatan emosional antara orang tua dan bayinya. Para orang tua kita telah melakukan pemijatan pada bayinya, dengan tujuan untuk menjaga kesehatan, melemaskan otot, ataupun kalau bayinya demam, meskipun para orang tua kita belum mengetahui dengan pasti manfaatnya, jadi bisa di katakan lebih kepada tradisi atau kepercayaan. Dalam pengembangan massage, penulis ingin mengenalkan bahwa ada beberapa cara atau metode yang di lakukan diantaranya:

1). Perahan Cara India.

Arah pijatan cara india ialah pijatan yang menjauhi tubuh. Guna pemijatan cara ini adalah utuk relaksasi atau melemaskan otot. Dengan gerakan tangan kanan dan kiri kebawah secara bergantian dan berulang-ulang seolah memerah susu sapi (Roseli, 2001).

2). Perahan Cara Swedia.

Arah pijatan cara swedia adalah dari pergelangan tangan ke arah badan. Pijatan ini berguna untuk mengalirkan darah ke jantung dan paru-paru. Dengan gerakan tangan kanan dan kiri tarapist secara bergantian mulai dari pergelangan tangan kanan bayi ke arah pundak. Kemudian lanjutkan dengan pijitan dengan pijitan dari pergelangan kiri bayi ke arah pundak (Subakti dan Rizky, 2009).

3). Pijat Tradisional Cara Jawa.

Pemijat terhadap anak kecil, yakni bayi sampai dengan balita, disebut dadah. Istilah pijit memang tidak terlalu tepat, karena pada bayi misalnya, sama sekali tidak boleh dipijat tetapi hanya dipegang-pegang saja. Pemijatan harus selalu dilakukan dari bagian-bagian badan yang letaknya berjauhan dari letak jantung. Misalnya, bagian ujung kaki dulu, atau ujung jari dulu. Ada bagian-bagian tubuh bayi yang harus di perlakukan dengan ekstra hati-hati. Bagian-bagian itu kepala, terutama disekitar ubun-ubunnya. Sepanjang tulang belakang juga tergolong bagian yang rawan. Dan yang terakhir daerah dada (Roseli, 2001).

4). Pijat cina.

Pijat adalah tentang sentuhan. Kita ketahui bahwa energi seorang anak mudah di capai, dan pijat yang di lakukan tidak membutuhkan tekanan kuat agar efektif. Dengan menggunakan teknik gerakkan yaitu:

a. Teknik tekan, teknik ini melibatkan penggunaan tekanan ringan dan diam pada titik tertentu. Dengan menggunakan ibu jari, jari tengah atau telapak tangan untuk menekan titik.

b. Teknik dorong, menggunakan jari-jari tunggal atau kombinasi ibu jari, telunjuk dan jari tengah dan sisi telapak tangan untuk mendorong dengan kuat pada arah yang berhubungan dengan titik. Teknik ini harus ringan dan cepat dan bergerak kearah membentuk garis sepanjang titik atau meridian

\section{METODE PELAKSANAAN}

Dalam rangka mencapai tujuan yang telah diuraikan di atas, maka pelaksanaan kegiatan pengabdian kepada masyarakat ini dilakukan dengan metode ceramah dan diskusi yaitu memberikan penjelasan dan praktik dari apa yang telah disampaikan. Ada dua metode yang di terapkan dalam program ini, yaitu metode presentasi, dan metode demonstrasi. Metode presentasi diterapkan untuk memperkenalkan teknik massage pada bayi usia $0-6$ bulan. 
1. Pra Kegiatan

a. Proses perijinan dimulai dengan membuat surat ijin dari universitas di tujukan aparat desa terkait tempat pengabdian dilakukan untuk melaksanakan program, Sekaligus meminta bantuan untuk memeperoleh data warga yang akan mengikuti program sosialisasi dan pelatihan.

b. Persiapan tempat di lakukan di ruangan Psyandu Permata Hati, RW 04 sekaligus perlengkapan pelatihan.

c. Persiapan alat, bahan dan perlengkapan dalam program ini dari mulai baby oil, alas bayi, modul, banner, laptop, papan tulis, dan bolpoint. Penyusunan alat evaluasi berupa daftar kehadiran, lembar latihan, lembar contoh lembar pertanyaan.

2. Pelaksanaan kegiatan

Setelah memeperoleh ijin dari pihak terkait serta diperolehnya data dari peserta maka dilaksanakan sosialisasi program dengan peserta dan instansi terkait, lalu dibuat kesepakatan mengenai waktu pelaksanaan. Berikut serangkaian kegiatan yang akan dilaksanakan dalam pengabdian antara lain: penjelasan menegnai manfaat dan kemudian pelaksanaan praktik pijat bayi.

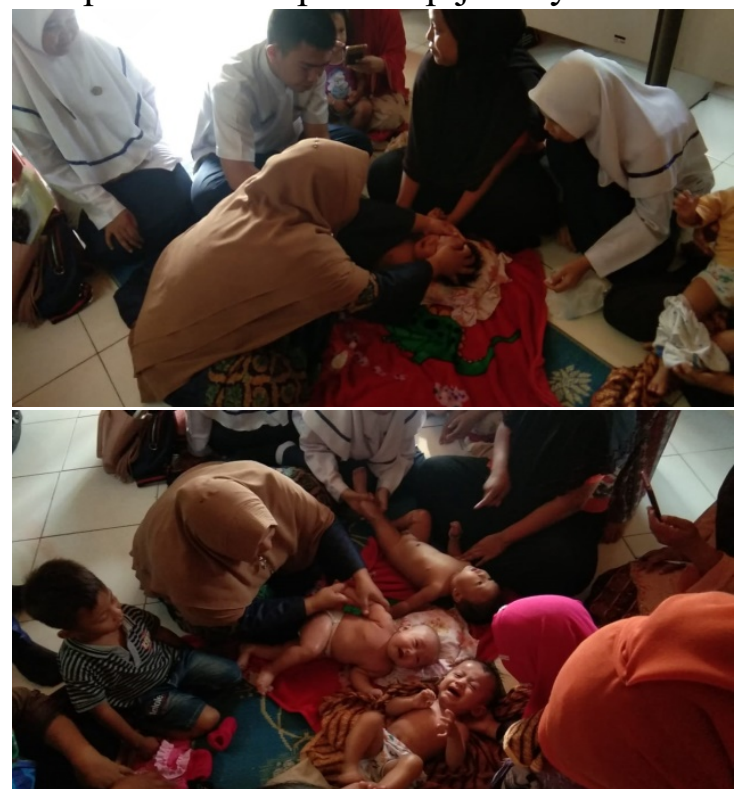

Gambar 1. Pelaksana Kegiatan Pengabdian

\section{HASIL DAN PEMBAHASAN}

Pengabdian ini dilaksanakan pada 8 Januari 2019, jam 09.00 WIB dengan tujuan untuk meningkatkan peran serta Fakultas Kedokteran dan ilmu kesehatan, Khususnya Progam studi Fisioterapi Universitas Abdurrab dalam memberikan pengetahuan dan informasi kepada orangtua, tentang teknik pemberian massage bayi terhadap peningkatan kualitas tidur bayi pada bayi normal usia $0-6$ bulan. Prosedur yang dilakukan dalam Pengabdian ini adalah perkenalan dengan pihak posyandu Permata Hati pada hari pertama pengabdian, kemudian pada hari kedua pengabdian dengan izin dari instansi terkait, tim memberikan materi.

Peserta berjumlah 13 orang yaitu ibu yang membawa bayi. Pertama diberikan demontrasi untuk teknik massage yang digunakan, kemudian semua peserta yang ikut dalam pelatihan ini secara aktif dan antusias melakukan demontrasi dan mereka saling berbagi untuk mengerjakan bagian-bagian pembelajaran mengenai teknik massage. 


\section{KESIMPULAN}

Program pengabdian ini bermanfaat sebagai sumber daya yang strategis oleh berbagai pihak terutama para pengambil kebijakan, dalam membuat perencanaan, pelaksanaan program dan mengevaluasi upaya-upaya kesehatan dengan memberikan massage bayi usia 0-6 bulan. Progam penyuluhan ini untuk memberikan edukasi kepada masyarakat teknik massage pada bayi usia 0-6 bulan. Kegiatan pengabdian maasyarakat ini berjalan dengan baik dan lancer sesuai yang di jadwalkan. Pada saat kegiatan pengabdian ini banyak para ibu yang antusias hal ini terlihat dari banyaknya para ibu yang bertanya, mengikuti gerakan dan mengikuti demonstrasinya.

\section{DAFTAR PUSTAKA}

[5]. Abraham M.Rudolph, Julien I.E, Colin D.Rudolph, Buku Ajar Pediatric Rudolph (edisi 20, Buku Kedokteran EGC, Jakarta 2006) hal 111

[6]. A.Aziz Alimul hidayat, Ketrampilan dasar praktik klinik untuk kebidanan, prinsip pemenuhan kebutuhan istirahat dan tidur, (Salemba medika, Jakarta 2008).

[7]. Dewi handjani, Diah Kurniati dan Laila Andaryan Hadis, perawatan bayi baru, (panduan lengkap untuk ibu merawat bayi 0 - 6 bulan), seri Ayahbunda, (Jakarta: Aspira Pemuda, november 2010) hlm.57 dan http//www.google.com, dechcare.com/massage menolong bayi tidur lebih nyenyak, di ambil.10-2-2011

[8]. Dr Alan Heath dan Nicki Bainbridge, Baby massage, kekuatan menenangkan dari sentuhan, (Dian Rakyat, jakarta 2006) hlm.12.

[9]. Kyle Cline, Pijat Cina Untuk Bayi dan Anak, (elexmedia komputindo, Jakarta 2001), hlm.36,39,42

[10]. Nurheti Yuliarti, keajaiban ASI (makanan terbaik untuk kesehatan, kecerdasan dan kelincahan sikeci), (Andi, Yogyakarta 2010) hlm. 4-5.

[11]. Siobhan Stirling, bayi tidur lebih lelap (panduan membantu anank tidur nyenyak), (Jakarta Erlangga.2003) hlm.10-12. Dan http://www.anakku.net, pola tidur dan kecerdasan anak. di ambil 12-3-2011.

[12]. Utami Roesli, pedoman pijat bayi, edisi revisi, (Jakarta: Trubus Agriwidya, 2001) hlm.23.

[13]. Widya Ayu puspita, menata kamar bayi, (agar bayi sehat dan nyaman), (Jakarta, Niaga swadaya 2006) hlm.8.

[14]. Wiiliam Sears, dan Martha sears, the Baby Book, (segala hal yang perlu anda ketahuitentang bayi anda sejak lahir hingga usia dua tahun),(serambi ilmu semesta, Jakarta 2009) hlm.421-422.

[15]. Yazid Subakti dan Deri Rizky Anggraini, Keajaiban Pijat Bayi dan Balita, (Wahyu Media, Jakarta, 2009), hlm.73 